\title{
In vitro and in vivo Protection against Indomethacin-Induced Small Intestinal Injury by Proton Pump Inhibitors, Acid Pump Antagonists, or Indomethacin-Phosphatidylcholine
}

\author{
Yun Jeong Lim ${ }^{\mathrm{a}-\mathrm{c}}$ Tri M. Phan ${ }^{\mathrm{a}}$ Elizabeth J. Dial ${ }^{\mathrm{a}}$ David Y. Graham ${ }^{\mathrm{b}}$ \\ Lenard M. Lichtenberger ${ }^{a}$ \\ ${ }^{a}$ Department of Integrative Biology and Pharmacology, The University of Texas Medical School at Houston, and \\ ${ }^{b}$ Department of Medicine, Michael E. DeBakey Veterans Affairs Medical Center and Baylor College of Medicine, \\ Houston, Tex., USA; ' Department of Internal Medicine, Dongguk University, Graduate School of Medicine, \\ Seoul, Korea
}

\section{Key Words}

Indomethacin · Small intestinal injury $\cdot$ Proton pump inhibitor $\cdot$ Acid pump antagonist $\cdot$ Phosphatidylcholine

\begin{abstract}
Background/Aims: Proton pump inhibitors (PPIs) are widely used to prevent nonsteroidal anti-inflammatory drug (NSAID)-induced peptic ulcers. NSAIDs produce small intestinal injury and some PPIs have been reported to protect against NSAID-induced small bowel injury in rats. The aim of this study was to compare PPIs, revaprazan, and phosphatidylcholine-associated indomethacin (Indo-PC) for protection against indomethacin (Indo)-induced small bowel injury. Methods: Rat intestinal epithelial cells (IEC-6) were pretreated with omeprazole, lansoprazole, or revaprazan prior to exposure to Indo or Indo-PC. Cell viability was assessed by methyl thiazolyl tetrazolium assay. Omeprazole, lansoprazole, or revaprazan was administered orally to rats prior to the vehicle or Indo. Indo-PC was administered alone. After $24 \mathrm{~h}$, small intestinal erosions were counted; intestinal bleeding was assessed as the hemoglobin concentration of small intestinal fluid. Results: Omeprazole, lansoprazole, and revaprazan did not protect against Indo-induced IEC- 6 cell in-
\end{abstract}

jury. Indo-PC was less damaging in vitro than Indo alone. In vivo, neither omeprazole nor lansoprazole protected against Indo-induced small bowel injury; however, revaprazan pretreatment and Indo-PC resulted in significantly fewer erosions ( $>50 \%$ reduction) or bleeding ( $>80 \%$ reduction). Conclusion: PPIs showed no small bowel protective effect in vitro or in vivo. Revaprazan showed a small bowel protective effect in vivo, whereas Indo-PC was protective both in vitro and in vivo.

Copyright $\odot 2012$ S. Karger AG, Basel

\section{Introduction}

Nonsteroidal anti-inflammatory drugs (NSAIDs) are extensively used for their analgesic, antipyretic, and antiinflammatory properties. However, NSAIDs can induce gastrointestinal (GI) injury which is an important issue in clinical practice. Proton pump inhibitors (PPIs) are widely used to reduce NSAID-induced peptic ulcers and are currently recommended for the prevention of NSAIDinduced peptic ulcers in high risk groups [1]. NSAID-induced small intestinal injury has been reported in 60$70 \%$ of users [2-5]. Although NSAID-induced small in-

\section{KARGER}

Fax +4161306 1234

E-Mail karger@karger.ch

www.karger.com (c) 2012 S. Karger AG, Basel

$0012-2823 / 12 / 0862-0171 \$ 38.00 / 0$

Accessible online at:

www.karger.com/dig
Elizabeth J. Dial

Department of Integrative Biology and Pharmacology

The University of Texas Medical School at Houston, 6431 Fannin

Houston, TX 77030 (USA)

Tel. +1 713500 6318,E-Mail Elizabeth.J.Dial@uth.tmc.edu 
testinal injury is typically asymptomatic, it can result in clinical outcomes such as overt bleeding, stricture, or small bowel perforation. The pathophysiologic mechanism of small intestinal injury induced by NSAIDs has not been fully elucidated, and reliably protective drugs have not been identified.

Recently, studies in rats have shown that some PPIs play a protective role against NSAID-induced small intestinal injury via anti-inflammatory and antioxidant mechanisms, and not by the suppression of acid secretion [6-8]. However, in other studies, PPIs have been reported to exacerbate NSAID-induced lower gut injury [9]. This paper sought to test and compare the effects of an acid pump antagonist (APA), revaprazan [10], and administration of the NSAID indomethacin (Indo) linked to phosphatidylcholine (PC) (i.e. the PC-associated NSAIDs Indo, Indo-PC) [11]. Protection against Indo-induced small intestinal injury was evaluated using both in vitro and in vivo systems.

\section{Methods}

\section{Materials}

Omeprazole was purchased from LKT laboratories Inc. (St. Paul, Minn., USA), and lansoprazole and Indo were purchased from Sigma-Aldrich (St. Louis, Mo., USA). Revaprazan was a gift from Yuhan Corp. (Seoul, South Korea). Indo-PC was prepared according to published protocols [11] and was a 1:2 preparation (by weight) of Indo and Phospholipon 90G (Lipoid Corp., Germany).

\section{In vitro System}

To assess whether there was a direct protective effect of drugs in vitro, we conducted the following experiments: rat intestinal epithelial cells (IEC-6) were maintained in Dulbecco's modified Eagle's medium (DMEM) containing 10\% fetal bovine serum, $4 \mu \mathrm{g} / \mathrm{ml}$ insulin, and penicillin/streptomycin under a humidified atmosphere containing $5 \% \mathrm{CO}_{2}$ at $37^{\circ} \mathrm{C}$. Cells were studied in $24-$ well tissue culture plates starting with $10^{5}$ cells per well. Omeprazole, lansoprazole, and revaprazan were solubilized in dimethyl sulfoxide and diluted at least 100-fold in DMEM media for cell studies. We determined beforehand that DMSO neither injured nor protected cells at the concentrations and times used. Indo was solubilized by forming the sodium salt, and Indo-PC was resuspended by vortex and sonication in phosphate-buffered saline prior to dilution in DMEM. Initially, we determined the maximum concentration of omeprazole, lansoprazole, and revaprazan which did not affect cell viability over $24 \mathrm{~h}$ of exposure. Next, the concentration of Indo showing $50 \%$ cell viability compared to the saline control following exposure for $24 \mathrm{~h}$ was determined. Using these optimized concentrations, omeprazole, lansoprazole, and revaprazan were incubated on IEC- 6 cells for $1 \mathrm{~h}$ prior to Indo addition and incubation was continued for $24 \mathrm{~h}$. An equivalent concentration of Indo-PC was used alone for $24 \mathrm{~h}$.
Cell viability was assessed by 3-(4,5-dimethyl-2-thiazolyl)2,5-diphenyl-2H-tetrazolium bromide (MTT) uptake into live cells. The MTT assay was performed on the plated cells by incubation with $0.05 \%$ MTT in media for $2 \mathrm{~h}$ using a previously reported protocol [12].

Indo-induced apoptosis was measured using Apo-ONE Caspase-3/7 Assay kits (Promega Corp., Madison, Wisc., USA) according to the manufacturer's instructions. Following cell incubations as described above, the assay reagent was added to cultures and fluorescence was measured after $1.5 \mathrm{~h}$.

\section{In vivo System}

Approval for all protocols was obtained from the institutional Animal Welfare Committee which follows the guidelines of and is accredited by the US Public Health Service. Male Sprague-Dawley rats (Harlan Sprague-Dawley, Indianapolis, Ind., USA) were used in all studies. Animals were maintained on a 12-hour light/ dark cycle with food and water provided ad libitum, except as noted. Sprague-Dawley rats (male, $\mathrm{n}=72$, average weight $=298 \mathrm{~g}$ ) were used to investigate the protective role of each drug against Indo in vivo. Omeprazole, lansoprazole, and revaprazan were suspended in $0.5 \%$ carboxymethylcellulose for oral administration ( $1 \mathrm{ml} / \mathrm{rat}$ ). Omeprazole (30 and $100 \mathrm{mg} / \mathrm{kg}$ ), lansoprazole (30 and $100 \mathrm{mg} / \mathrm{kg})$, and revaprazan $(30 \mathrm{mg} / \mathrm{kg})$ were administered orally 30 min prior to Indo. Indo was dissolved in $1.25 \%$ sodium bicarbonate to $2.5 \mathrm{mg} / \mathrm{ml}$, and the $\mathrm{pH}$ was adjusted to 7.4 before oral administration ( $10 \mathrm{mg} / \mathrm{kg}$ or $1 \mathrm{ml} / 250 \mathrm{~g}$ body weight). To confirm a therapeutic effect of each PPI, in separate experiments we measured the gastric fluid $\mathrm{pH}$ one hour after PPIs had been administered to rats. At PPI doses of $100 \mathrm{mg} / \mathrm{kg}$ the gastric fluid $\mathrm{pH}$ was maintained at $>6.8$, compared to control values of $\mathrm{pH}<4$. IndoPC $(10 \mathrm{mg} / \mathrm{kg})$ was administered orally to rats after dispersion by vortex and sonication in saline.

Rats were sacrificed $24 \mathrm{~h}$ after Indo administration to determine small intestinal injury. The entire small intestine was resected along the antimesenteric border and visually examined along its length. A segment of $15 \mathrm{~cm}$ that included the most severe lesions was selected from the distal half of the small intestine and erosions were counted independently by two persons (e.g. number of erosions $/ 15 \mathrm{~cm}$ ). We calculated the number of erosions using the sum of longitudinal lengths.

Intestinal bleeding was assessed by the measuring the hemoglobin $(\mathrm{Hb})$ concentration of small intestinal fluid collected by flushing $8 \mathrm{ml}$ of normal saline followed by $2 \mathrm{ml}$ of air through the lumen of the whole small intestine. The intestinal fluid $\mathrm{Hb}$ level was measured by a modification of the benzidine method as previously reported $[13,14]$.

Experiments were analyzed initially by one-way ANOVA, followed by post hoc testing with the Fisher LSD test. $p<0.05$ was considered statistically significant.

\section{Results}

\section{In vitro System}

The cell viability was dose-dependently reduced by increasing concentrations of Indo (fig. 1a). The concentration of Indo that reduced cell viability by $50 \%$ compared 

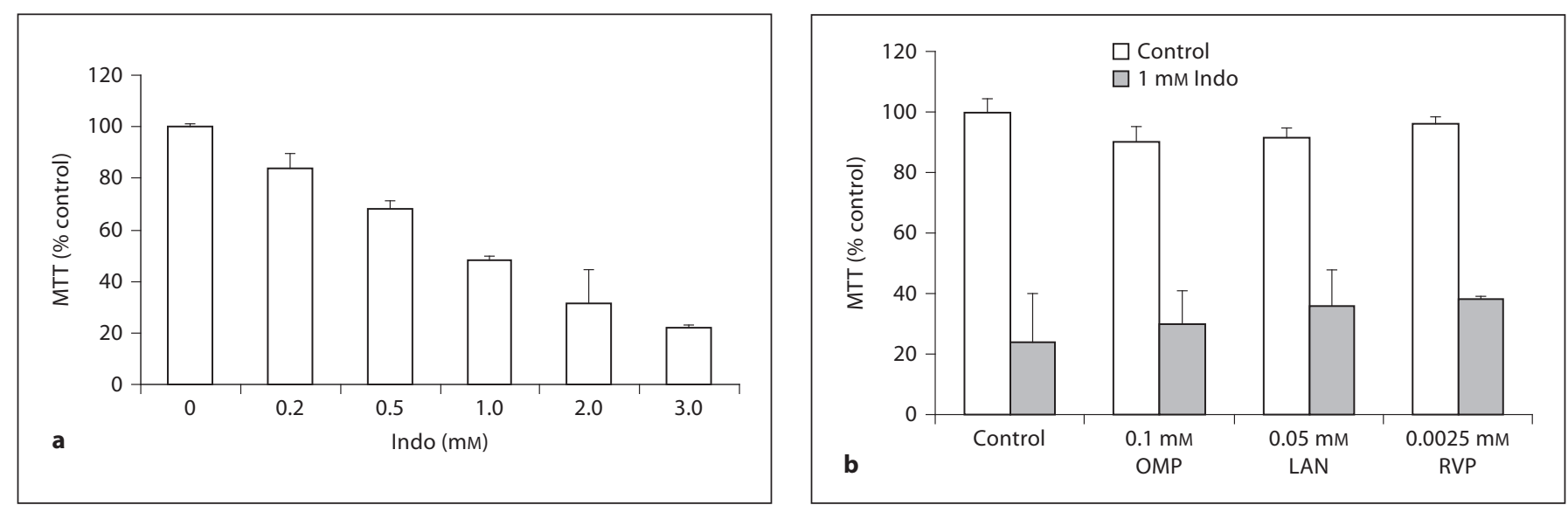

Fig. 1. In vitro studies - Indo. a MTT assay showed that Indo decreased cell viability in a dose-dependent manner. b MTT assay showed that omeprazole (OMP), lansoprazole (LAN), and revaprazan (RVP) did not reverse the Indo-induced reduction of intestinal cell viability.
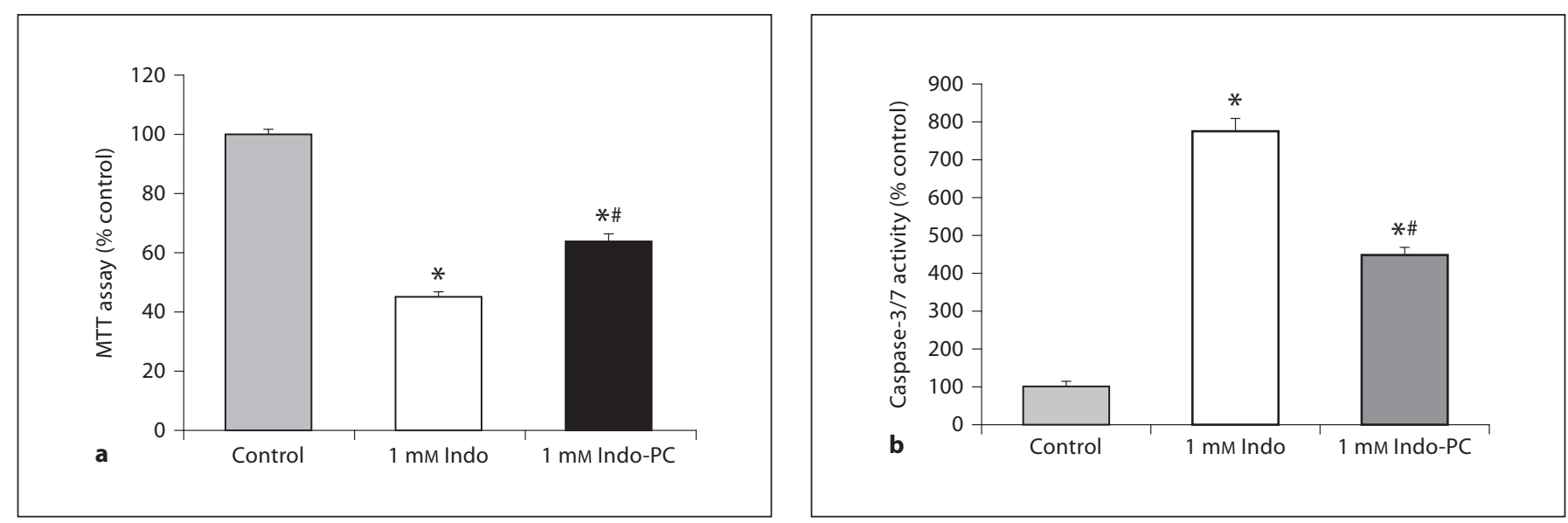

Fig. 2. In vitro studies - Indo-PC. a MTT assay showed that Indo-PC at $1 \mathrm{mM}$ was less injurious than Indo alone. b Caspase-3/7 assay showed that Indo-PC induced less apoptosis than Indo alone. ${ }^{*} \mathrm{p}<0.001$ versus control; ${ }^{\#} \mathrm{p}<0.001$ versus Indo.

to the untreated control was $1 \mathrm{mM}$ and it was used in further studies. The concentrations of drug that did not affect viability were $0.1 \mathrm{mM}$ of omeprazole, $0.05 \mathrm{mM}$ of lansoprazole, or $0.0025 \mathrm{mM}$ of revaprazan (data not shown). MTT assays showed that omeprazole, lansoprazole, and revaprazan failed to protect against $1 \mathrm{~mm}$ Indo-induced intestinal cell injury (fig. 1b). In contrast, Indo-PC at $1 \mathrm{mM}$ was significantly less damaging (approx. 35\%) than Indo alone (fig. 2a). Using caspase-3/7 activity as a marker of apoptosis also showed that Indo-induced apoptosis was significantly less with Indo-PC compared to Indo alone (fig. 2b).

In vitro and in vivo Protection against Indo-Induced Small Intestinal Injury

\section{In vivo System}

\section{Gross Small Intestinal Lesion Scores}

When administered to rats, Indo at $10 \mathrm{mg} / \mathrm{kg}$ caused small intestinal injury consisting of punctuate hemorrhagic spots or erosions on the small intestinal mucosa (fig. 3a). There was no concomitant stomach or large intestinal injury during the same time frame in this rat model. Because pretreatment with lansoprazole or omeprazole $(30 \mathrm{mg} / \mathrm{kg})$ did not reduce Indo-induced small intestinal injury (not shown), a higher dose of 100 $\mathrm{mg} / \mathrm{kg}$ of each PPI was used. Even at this higher dose, neither PPI protected against Indo-induced intestinal injury 


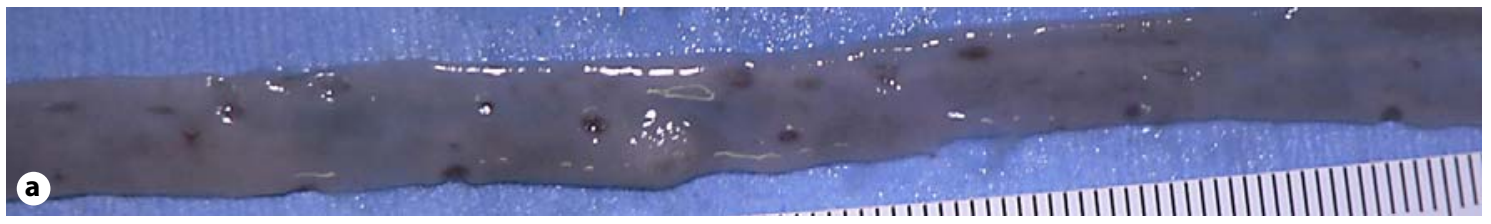

Fig. 3. In vivo studies - lesions. a A $10 \mathrm{mg} /$ $\mathrm{kg}$ dose of Indo produced punctate hemorrhagic spots and small punch-out lesions on the small intestine in rats. b Small intestinal lesion scores. Omeprazole and lansoprazole pretreatment did not alter the Indo-induced mucosal lesion score, while revaprazan pretreatment tended to reduce the lesion score $(\mathrm{p}=0.06)$. Indo-PC showed significantly fewer gross small intestine mucosal lesions than Indo alone $\left({ }^{*} \mathrm{p}<0.05\right)$.

(fig. 3b). In contrast, revaprazan pretreatment $(30 \mathrm{mg} / \mathrm{kg})$ apparently reduced the small intestinal lesion scores by approximately $50 \%$, although it did not reach statistical significance $(\mathrm{p}=0.06)$. Indo-PC $(10 \mathrm{mg} / \mathrm{kg})$ was also associated with markedly fewer small intestinal lesions (a reduction of more than $80 \%$; $\mathrm{p}<0.05$ ) compared to the Indo-alone group (fig. 3b).

\section{HB Assay of Small Intestinal Fluid}

Vehicle control (carboxymethycellulose) produced a very low $\mathrm{Hb}$ concentration similar to that in the saline control group (data not shown). In contrast, Indo treatment significantly increased the intestinal fluid $\mathrm{Hb}$ concentration, while lansoprazole and omeprazole pretreatment prior to administration of Indo induced a release of $\mathrm{Hb}$ in the intestinal fluid that was similar to the levels observed in response to the administration of Indo alone (fig. 4). Both the revaprazan pretreatment group and the Indo-PC group showed a significant reduction in intestinal fluid $\mathrm{Hb}$ concentration (i.e. over $80 \%$ ) compared to Indo alone $(\mathrm{p}<0.05)$.

\section{Discussion}

NSAIDs have been widely used for decades to relieve pain, inflammation, and fever. However, the main factor that limits use of NSAIDs are the GI side effects of dys-
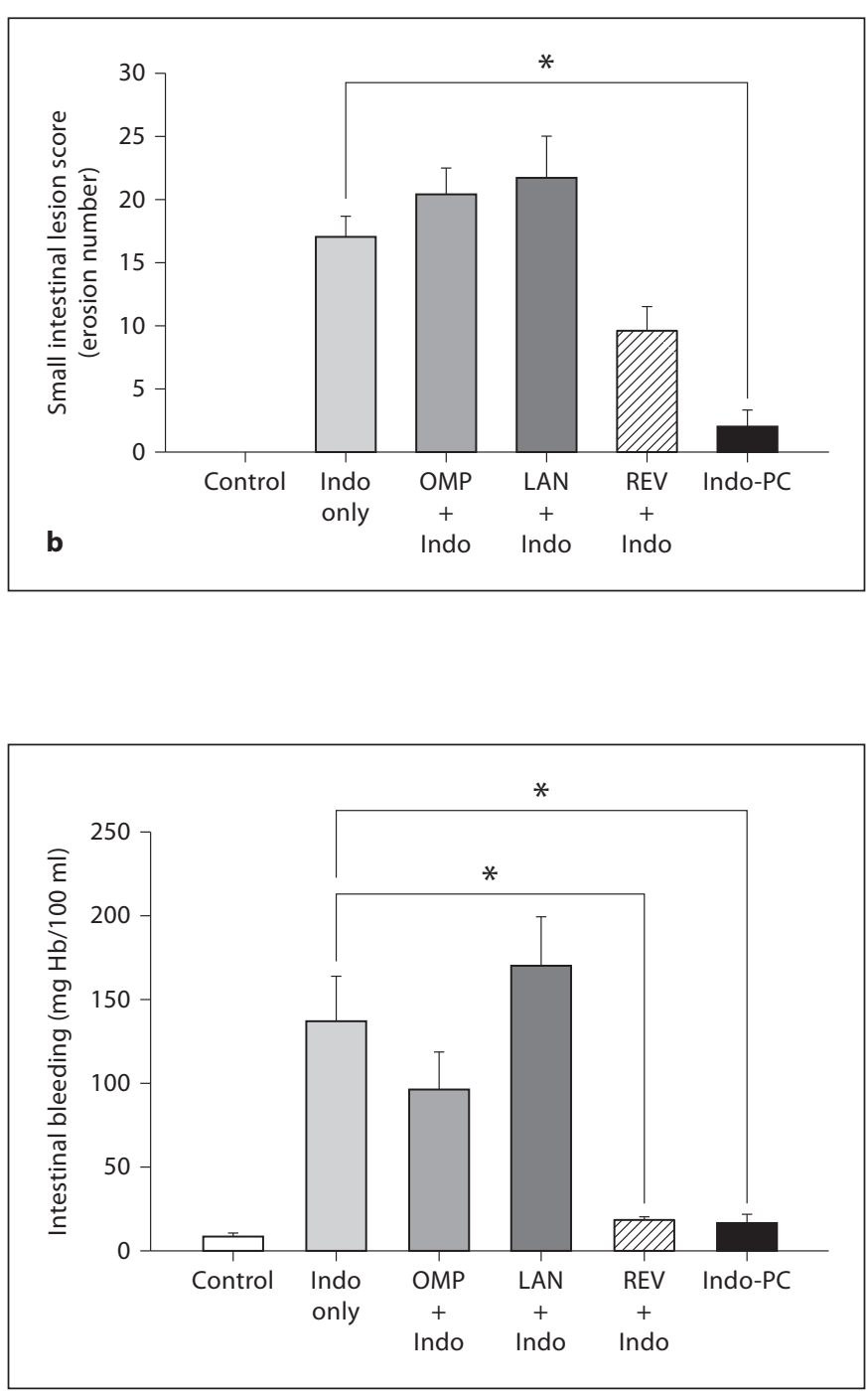

Fig. 4. In vivo studies - bleeding. Intestinal fluid $\mathrm{Hb}$ assay. The revaprazan pretreatment group and the Indo-PC group had statistically significant decreased $\mathrm{Hb}$ levels of the collected intestinal fluid compared to the Indo-alone group $\left({ }^{*} \mathrm{p}<0.05\right)$. In contrast, omeprazole, and lansoprazole did not reduce the intestinal bleeding induced by Indo.

pepsia, bleeding, and peptic ulceration. Although the adverse side effects of NSAIDs on the upper GI tract are well known, NSAID-induced small intestinal injury is less appreciated and, although the small intestine may be a com- 
mon site for NSAID toxicity, injury is generally asymptomatic and it is difficult to detect using conventional endoscopic methods. However, newly developed diagnostic modalities such as capsule endoscopy and double balloon enteroscopy have identified NSAID enteropathy as an emerging problem. For example, several recent studies have reported that lower GI events accounted for one third of all clinically relevant GI events and that NSAIDinduced lower GI complications (perforation, bleeding, obstruction) are increasing while upper GI complications are decreased. In fact, the ratio of upper/lower GI complications was 4.1 in 1996 but only 1.4 in 2005 [15] and it has been suggested that the incidence of lower GI complications is now similar to that observed in the upper GI tract [15].

Unlike upper GI toxicity, cyclooxygenase-mediated mechanisms of the small intestine may be less important. The pathophysiologic mechanism of NSAID enteropathy is not fully elucidated. Factors involved include: (1) NSAID-induced direct damage of enterocyte mitochondria during absorption by uncoupling of mitochondrial oxidative phosphorylation [16], (2) increased intestinal motility [17], (3) NO derived from induced iNOS [18-20], (4) increased small intestinal permeability [16], and (5) luminal aggressive factors including bile, hydrolytic and proteolytic enzymes, bacterial degradation products, bacterial invasion of the mucosa, and enterohepatic circulation of NSAID [21-23].

Up to now, no medications have been shown to reliably and specifically prevent or heal NSAID-induced small intestinal injury. However NSAIDs may differ in their tendency to produce small bowel injury. For example, selective COX-2 inhibition with celecoxib after short-term (2 weeks) use had fewer mucosal breaks when compared to naproxen plus omeprazole but no improvement in intestinal permeability [24]. However, subjects with more than 3 months of selective COX-2 inhibition with a variety of coxibs developed injury similar to that with nonselective COX inhibition [3]. In a 6-month trial of celecoxib versus enteric-coated diclofenac plus omeprazole, there were fewer cases of clinically significant GI events with celecoxib compared to the nonselective NSAID; however, mucosal injury or permeability were not directly examined [25]. Capsule endoscopy showed that misoprostol (prostaglandin $\mathrm{E}_{2}$ ) co-administration with the NSAID diclofenac was associated with significantly fewer small bowel mucosal breaks than NSAID administration [26]. Misoprostol also decreased low-dose aspirin-induced small bowel injuries [27]. Rebamipide, a so-called mucosal protective agent, has also been reported to prevent di-

In vitro and in vivo Protection against Indo-Induced Small Intestinal Injury clofenac-induced small bowel injury as observed with capsule endoscopy after 7 days of treatment in healthy patients [28]. There was also a tendency for protection in a 2-week trial but it did not achieve statistical significance [29]. In a similar trial design against a 1-week diclofenac challenge, the antiulcer drug geranylgeranylacetone also provided significant intestinal protection [30], but it has not been further evaluated for more long-term efficacy.

A number of animal studies where protection against NSAID-induced intestinal injury was examined have reported that both recombinant human lactoferrin [31] and the probiotic Lactobacillus casei strain Shirota [32] exerted intestinal protection against Indo and other NSAIDs.

PPIs are widely available and there have been reports [6-8] that lansoprazole prevented Indo-induced small intestinal injury in a rat model by upregulation of heme oxygenase-1 producing anti-inflammatory and antioxidative responses. Here we conducted experiments to elucidate whether PPIs in comparison to an APA could protect against NSAID-induced intestinal injury. We were unable to confirm a protective effect of traditional PPIs against Indo-induced intestinal injury in an acute rodent model system. PPIs also did not prevent Indo-induced cell injury in vitro. The explanation for this lack of protection is not clear, as we attempted to replicate the published study conditions. It has been reported that chronic use of PPI can shift bacterial flora in the intestine and that this PPI-induced dysbiosis can aggravate NSAID enteropathy [9]. Whether this dysbiosis can occur $24 \mathrm{~h}$ after only one PPI dose as in our studies appears unlikely but remains to be investigated further. We did, however, attempt to eliminate some possible explanations for the lack of a PPI protective effect. For example, gastric $\mathrm{pH}$ was measured to confirm that the PPI doses tested produced an appropriate antisecretory effect. Also, controls for the vehicle (carboxymethycellulose) showed that this solution itself was not toxic to the small intestine. Thus, contrary to previous reports, we found that PPIs had no protective effect against NSAID-induced intestinal injuries.

Revaprazan (YH-1885), 5,6-dimethyl-2-(4-fluorophenylamino)-4-(1-methyl-1, 2, 3, 4-tetrahydroisoquinoline-2-yl) pyrimidine hydrochloride, is an APA that is currently approved by the Korean Food and Drug Administration as a new drug for the treatment of gastric diseases including peptic ulcer and gastritis [10, 33]. Revaprazan competes with $\mathrm{K}^{+}$on the proton pump and represents a reversible model of action against $\mathrm{H}^{+} / \mathrm{K}^{+}$ATPase, which is distinct from that of PPIs known for 
irreversible inhibition. The other advantage of this APA is its fast onset of action as it does not need to be converted to an active form, and it has a high selective affinity for $\mathrm{H}^{+} / \mathrm{K}^{+}$ATPase. Revaprazan has been shown to prevent NSAID-induced gastropathy through the preservation of heat shock protein 27 in a rat model [34]. However, in present study, we failed to find any significant change of heat shock protein (heat shock protein 24,70 ) in the revaprazan pretreatment group. Our results showed that revaprazan did not directly protect against Indo-induced intestinal cell injury in the IEC- 6 cell line. However, it was effective at reducing intestinal bleeding in the in vivo rat experiment. The protective effect of revaprazan may be indirect and unrelated to acid inhibition, as the PPI drugs did not show similar protection. The underlying pathophysiologic mechanism of the protective effect of revaprazan remains to be elucidated.

Bile acids augment Indo-induced GI toxicity in vivo [35-37]. This toxicity of Indo with bile acids has also been shown in vitro cell systems [12]. The cytotoxic action of NSAIDs in combination with natural bile and/or synthetic bile acids can be reversed in a dose-dependent fashion by the addition of PC [38]. Therefore, it follows that Indo that is preassociated with PC (Indo-PC) may have less GI toxicity than the NSAID alone. Previous animal studies have indeed shown that Indo-PC has little GI toxicity and has similar anti-inflammatory, analgesic, and bioavailability properties compared to Indo [11]. The results of the current study showed that Indo-PC was noninjurious in vivo. The mechanism for less injury by IndoPC may be related to a proposed membrane-perturbing effect of Indo [12] which could be prevented by PC. In vitro studies showed that Indo-PC resulted in a higher vi- ability of IEC- 6 cells compared to Indo when measured using the MTT assay, supporting a reduction in the direct injurious action of Indo. It has been reported by others [39] that a 16-hour incubation of GI cells with $0.5-1 \mathrm{mM}$ Indo results in apoptosis. We assessed the apoptotic activity of both Indo and Indo-PC and found that Indo-PC produced less apoptotic activity leading to reduced programmed cell death. We speculate that a less membrane injurious effect of Indo-PC may contribute to a reduced toxicity over time, and that reduced apoptosis may be either a direct effect or a reflection of this lower toxicity.

In summary, we report that PPIs failed to protect the small intestine from Indo-induced injury. In contrast, the APA revaprazan was protective. We also showed that, in contrast to the parent NSAID, PC-associated Indo also was less injurious to the small intestine. Both revaprazan and Indo-PC should be further evaluated for protective activity against NSAID-induced intestinal injury.

\section{Acknowledgements}

The study was supported in part by NIH grant RC1DK086304, P30DK056338, and Yuhan Corp. Dr. Graham is supported in part by the Office of Research and Development Medical Research Service Department of Veterans Affairs. Dr. Lichtenberger and Dr. Graham are supported in part by Public Health Service grant DK56338 which funds the Texas Medical Center Digestive Diseases Center.

\section{Disclosure Statement}

Dr. Lichtenberger is a stockholder and consultant to PLx Pharma Inc. which is developing Indo-PC for therapeutic uses.

\section{References}

1 Scarpignato C, Hunt RH: Nonsteroidal antiinflammatory drug-related injury to the gastrointestinal tract: clinical picture, pathogenesis, and prevention. Gastroenterol Clin North Am 2010;39:433-464.

2 Graham DY, Opekun AR, Willingham FF, Qureshi WA: Visible small-intestinal mucosal injury in chronic NSAID users. Clin Gastroenterol Hepatol 2005;3:55-59.

-3 Maiden L, Thjodleifsson B, Seigal A, Bjarnason II, Scott D, Birgisson S, Bjarnason S: Long-term effects of nonsteroidal anti-inflammatory drugs and cyclooxygenase- 2 selective agents on the small bowel: a cross-sectional capsule enteroscopy study. Clin Gastroenterol Hepatol 2007;5:1040-1045.
4 Maiden L: Capsule endoscopic diagnosis of nonsteroidal antiinflammatory drug-induced enteropathy. J Gastroenterol 2009;44: 64-71.

5 Caunedo-Alvarez A, Gomez-Rodriguez BJ, Romero-Vazquez J, Arguelles-Arias F, Romero-Castro R, Garcia-Montes JM, Pellicer-Bautista FJ, Herrerias-Gutierrez JM: Macroscopic small bowel mucosal injury caused by chronic nonsteroidal anti-inflammatory drugs (NSAID) use as assessed by capsule endoscopy. Rev Esp Enferm Dig 2010;102:80-85.

-6 Kuroda MN, Yoshida H, Ichikawa T, Takagi T, Okuda Y, Naito T, Okanoue T, Yoshikawa $\mathrm{T}$ : Lansoprazole, a proton pump inhibitor, re- duces the severity of indomethacin-induced rat enteritis. Int J Mol Med 2006;17:89-93.

-7 Pozzoli C, Menozzi A, Grandi D, Solenghi E, Ossiprandi MC, Zullian C, Bertini B, Cavestro GM, Coruzzi G: Protective effects of proton pump inhibitors against indomethacin-induced lesions in the rat small intestine. Naunyn Schmiedebergs Arch Pharmacol 2007;374:283-291.

$\checkmark 8$ Yoda Y, Amagase K, Kato S, Tokioka S, Murano $\mathrm{M}$, Kakimoto K, Nishio $\mathrm{H}$, Umegaki E, Takeuchi K, Higuchi K: Prevention by lansoprazole, a proton pump inhibitor, of indomethacin-induced small intestinal ulceration in rats through induction of heme oxygenase-1. J Physiol Pharmacol 2010;61:287-294. 
9 Wallace JL, Syer S, Denou E, de Palma G, Vong L, McKnight W, Jury J, Bolla M, Bercik P, Collins SM, Verdu E, Ongini E: Proton pump inhibitors exacerbate NSAID-induced small intestinal injury by inducing dysbiosis. Gastroenterology 2011;141:1314-1322.

10 Kim HK, Park SH, Cheung DY, Cho YS, Kim JI, Kim SS, Chae HS, Kim JK, Chung IS: Clinical trial: inhibitory effect of revaprazan on gastric acid secretion in healthy male subjects. J Gastroenterol Hepatol 2010;25:16181625.

11 Lichtenberger LM, Romero JJ, Dial EJ: Gastrointestinal safety and therapeutic efficacy of parenterally administered phosphatidylcholine-associated indomethacin in rodent model systems. Br J Pharmacol 2009;157: 252-257.

- 12 Zhou Y, Dial E J, Doyen R, Lichtenberger LM: Effect of indomethacin on bile acidphospholipid interactions: implication for small intestinal injury induced by nonsteroidal anti-inflammatory drugs. Am J Physiol Gastrointest Liver Physiol 2010;298:G722G731.

13 Lichtenberger LM, Wang ZM, Romero JJ, Ulloa C, Perez JC, Giraud MN, Barreto JC: Non-steroidal anti-inflammatory drugs (NSAIDs) associate with zwitterionic phospholipids: insight into the mechanism and reversal of NSAID-induced gastrointestinal injury. Nat Med 1995;1:154-158.

14 Crosby WH, Furth FW: A modification of the benzidine method for measurement of hemoglobin in plasma and urine. Blood 1956;11:380-383.

-15 Lanas A, Sopeña F: Nonsteroidal anti-inflammatory drugs and lower gastrointestinal complications. Gastroenterol Clin North Am 2009;38:333-352.

16 Bjarnason I, Hayllar J, MacPherson AJ, Russell AS: Side effects of nonsteroidal anti-inflammatory drugs on the small and large intestine in humans. Gastroenterology 1993; 104:1832-1847.

-17 Takeuchi K, Miyazawa T, Tanaka A, Kato S, Kunikata T: Pathogenic importance of intestinal hypermotility in NSAID-induced small intestinal damage in rats. Digestion 2002;66: $30-41$.

18 Whittle BJ, Laszlo F, Evans SM, Moncada S: Induction of nitric oxide synthase and microvascular injury in the rat jejunum provoked by indomethacin. Br J Pharmacol 1995; 116:2286-2290.

19 Konaka A, Nishijima M, Tanaka A, Kunikata T, Kato S, Takeuchi K: Nitric oxide, superoxide radicals and mast cells in pathogenesis of indomethacin-induced small intestinal lesions in rats. J Physiol Pharmacol 1999;50: $25-38$.
20 Tanaka A, Kunikata T, Mizoguchi H, Kato S, Takeuchi K: Dual action of nitric oxide in pathogenesis of indomethacin-induced small intestinal ulceration in rats. J Physiol Pharmacol 1999;50:405-417.

21 Robert A, Asano T: Resistance of germfree rats to indomethacin-induced intestinal lesions. Prostaglandins 1977;14:333-341.

22 Reuter BK, Davies NM, Wallace JL: Nonsteroidal anti-inflammatory drug enteropathy in rats: role of permeability, bacteria, and enterohepatic circulation. Gastroenterology 1997;112:109-117.

23 Watanabe T, Higuchi K, Kobata A, Nishio H, Tanigawa T, Shiba M, Tominaga K, Fujiwara Y, Oshitani N, Asahara T, Nomoto K, Takeuchi K, Arakawa T: Non-steroidal anti-inflammatory drug-induced small intestinal damage is Toll-like receptor 4 dependent. Gut 2008;57:181-187.

24 Goldstein JL, Eisen GM, Lewis B, Gralnek IM, Zlotnick S, Fort JG: Video capsule endoscopy to prospectively assess small bowel injury with celecoxib, naproxen plus omeprazole, and placebo. Clin Gastroenterol Hepatol 2005;3:133-141.

25 Chan FK, Lanas A, Scheiman J, Berger MF, Nguyen H, Goldstein JL: Celecoxib versus omeprazole and diclofenac in patients with osteoarthritis and rheumatoid arthritis (CONDOR): a randomised trial. Lancet 2010;376:173-179.

26 Fujimori S, Seo T, Gudis K, Ehara A, Kobayashi T, Mitsui K, Yonezawa M, Tanaka S, Tatsuguchi A, Sakamoto C: Prevention of nonsteroidal anti-inflammatory drug-induced small-intestinal injury by prostaglandin: a pilot randomized controlled trial evaluated by capsule endoscopy. Gastrointest Endosc 2009;69:1339-1346.

27 Watanabe T, Sugimori S, Kameda N, Machida $\mathrm{H}$, Okazaki $\mathrm{H}$, Tanigawa $\mathrm{T}$, Watanabe $\mathrm{K}$, Tominaga K, Fujiwara Y, Oshitani N, Higuchi K, Arakawa T: Small bowel injury by lowdose enteric-coated aspirin and treatment with misoprostol: a pilot study. Clin Gastroenterol Hepatol 2008;6:1279-1282.

28 Niwa Y, Nakamura M, Ohmiya N, Maeda O, Ando T, Itoh A, Hirooka Y, Goto H: Efficacy of rebamipide for diclofenac-induced smallintestinal mucosal injuries in healthy subjects: a prospective, randomized, doubleblinded, placebo-controlled, cross-over study. J Gastroenterol 2008;43:270-276.

-29 Fujimori S, Takahashi Y, Gudis K, Seo T, Ehara A, Kobayashi T, Mitsui K, Yonezawa M, Tanaka S, Tatsuguchi A, Sakamoto C: Rebamipide has the potential to reduce the intensity of NSAID-induced small intestinal injury: a double-blind, randomized, controlled trial evaluated by capsule endoscopy. J Gastroenterol 2011;46:57-64.
30 Niwa Y, Nakamura M, Miyahara R, Ohmiya $\mathrm{N}$, Watanabe $\mathrm{O}$, Ando T, Kawashima H, Itoh A, Hirooka Y, Goto H: Geranylgeranylacetone protects against diclofenac-induced gastric and small intestinal mucosal injuries in healthy subjects: a prospective randomized placebo-controlled double-blind crossover study. Digestion 2009;80:260-266.

31 Dial EJ, Dohrman AJ, Romero JJ, Lichtenberger LM: Recombinant human lactoferrin prevents NSAID-induced intestinal bleeding in rodents. J Pharm Pharmacol 2005;57: 93-99.

32 Watanabe T, Nishio H, Tanigawa T, Yamagami $\mathrm{H}$, Okazaki $\mathrm{H}$, Watanabe $\mathrm{K}$, Tominaga K, Fujiwara Y, Oshitani N, Asahara T, Nomoto K, Higuchi K, Takeuchi K, Arakawa T: Probiotic Lactobacillus casei strain Shirota prevents indomethacin-induced small intestinal injury: involvement of lactic acid. Am J Physiol Gastrointest Liver Physiol 2009; 297:G506-G513.

33 Yu KS, Bae KS, Shon JH, Cho JY, Yi SY, Chung JY, Lim HS, Jang IJ, Shin SJ, Song KS, Moon BS: Pharmacokinetic and pharmacodynamic evaluation of a novel proton pump inhibitor, YH1885, in healthy volunteers. J Clin Pharmacol 2004;44:73-82.

34 Ock CY, Lim YJ, Kim YJ, Chung JW, Kwon KA, Kim JH, Hahm KB: Acid pump antagonist-provoked HSP27 dephosphorylation and accentuation rescues stomach from indomethacin-induced damages. J Dig Dis 2011;12:71-81.

-35 Duggan DE, Hooke KF, Noll RM, Kwan KC: Enterohepatic circulation of indomethacin and its role in intestinal irritation. Biochem Pharmacol 1975;24:1749-1754.

36 Yamada T, Deitch E, Specian RD, Perry MA, Sartor RB, Grisham MB: Mechanisms of acute and chronic intestinal inflammation induced by indomethacin. Inflammation 1993; 17:641-662.

37 Jacob M, Foster R, Sigthorsson G, Simpson $\mathrm{R}$, Bjarnason I: Role of bile in pathogenesis of indomethacin-induced enteropathy. Arch Toxicol 2007;81:291-298.

38 Dial EJ, Darling RL, Lichtenberger LM: Importance of biliary excretion of indomethacin in gastrointestinal and hepatic injury. J Gastroenterol Hepatol 2008;23:e384-e389.

39 Tomisato W, Tsutsumi S, Rokutan K, Tsuchiya T, Mizushima T: NSAIDs induce both necrosis and apoptosis in guinea pig gastric mucosal cells in primary culture. Am J Physiol Gastrointest Liver Physiol 2001; 281:G1092-G1100. 